\title{
Una evasión romántica de Fernando Calderón
}

\begin{abstract}
$\mathbf{Q}$ UIEN recorre la historia de la literatura mexicana a través del siglo XIX, no sólo como lector que quiere conocerla sino con fines didácticos, para transmitir los conocimientos adquiridos y familiarizar a los oyentes con los autores de categoría, halla entre los problemas planteados por el primer romanticismo en México, los que se refieren a la vida y la obra de Fernando Calderón. Su biografía ofrece aún lagunas que la anécdota ha pretendido inútilmente llenar; permanece en parte velada por un halo, romántico también: la leyenda que Guillermo Prieto contribuyó a forjar, en Memorias de mis tiempos, y que Manuel Payno, quien pudo hacerlo como prologuista de sus obras, no disipó con los datos indispensables. Lo único que sabemos con certeza es que vivió Calderón -intensamente, como correspondía a un romántico — una existencia que abunda en contrastes: el buen camarada, que prodiga su ingenio en agudezas y sus recursos pecuniarios en obsequios; el valiente voluntario que se muestra generoso de su sangre al defender la tierra de los nayores, como dramaturgo parece ajeno a las preocupaciones de la gente con quien alterna, ya que sitúa la acción de casi todas sus obras de teatro, en tierras extrañas y épocas remotas. Sólo en una obra inconclusa, Los políticos del día, y en la comedia $A$ ninguna de las tres presenta personajes mexicanos. En la segunda, con la que responde a Marcela o ¿̇a cuál de los tres?, de Bretón, alude al afrancesamiento y critica la deficiente educación de las mujeres.

Al cumplirse el primer centenario de la muerte de Fernando Calderón, me propuse explorar los archivos, y fuí a Guadalajara con el fin de desvanecer aquellas dudas que persistían, como la re-
\end{abstract}


lacionada con el día de su nacimiento - acaecido en Guadalajara, Jalisco, el 26 de julio de 1809 - y la relativa al título de Conde de Santo Rosa, que jamás perteneció al poeta ni a su padre. Con el mismo propósito releí sus obras, y entonces hallé que el escaso conocimiento de algunas de ellas había dado-lugar a infundadas versiones que se han repetido varias veces.

No trataré aquí de su obra lírica, ya estudiada por Menéndez y Pelayo, quien afirmó que Calderón fué más bien poeta dramático que lírico, a la inversa de Rodríguez Galván, más lírico que dramático. Dentro de una actividad ininterrumpida desde hace tres décadas: el comentario de espectáculos teatrales, enfocaré un aspecto del teatro de Fernando Calderón, del cual, juzgado en conjunto por los historiadores de nuestra literatura, suele decirse que no está conectado con el medio y la época en que lo produjo. Como Rodríguez Galván presentó en sus dramas asuntos y personajes del virreinato, la crítica se ha creído obligada a dirigir reproches a Calderón, por no haber procedido en forma semejante. El maestro Altamirano escribió, en la primera de sus Revistas literarias: "Calderón, con su feliz imaginación y con su sentimentalismo, pudo haber ayudado al segundo a crear el teatro nacional; y no que fué a emplear sus dotes en resucitar asuntos caballerescos de la Edad Media, que ninguna utilidad podían traer, sino un fútil entretenimiento y un extravío de gusto, o bien fué a buscar en la historia dé Inglaterra un episodio que mejor inspirados habian ya trasladado al teatro algunos poetas europeos." Otros críticos, después, también lo censuraron porque prefirió situar en otros países la acción de esas obras. Sin embargo, el nacionalismo no falta — no podía faltar en un auténtico romántico- en otras producciones de Calderón. Aun sin asomarse a las líricas, donde "E1 soldado de la Libertad" y "El sueño del tirano" son claras pruebas de ello, basta recordar las dos mencionadas comedias, en las cuales el mexicanismo de Calderón se manifiesta a través de las opiniones de algunos personajes. $¿$ ¿Por qué sus obras dramáticas vienen a constituir una excepción, precisamente? Con anterioridad expuse mi parecer acerca de ello, en un estudio sobre Calderón y sus dramas, en el cual dije que'se "sale del marco habitual en nuestro teatro, no sólo porque sus lecturás y preferencias le llevaron a otros países y otros tiempos -evasión romántica-, sino porque la situación política le impedía tratar 
en serio la actualidad, en su época. Al preferir, con sus dramas, refugiarse en el pasado, quiso manifestar sin traba alguna elevados sentimientos que no cabían en un presente mezquino. Procedió como otro dramaturgo hispanoamericano de su tiempo: el argentino José Mármol, en El cruzado, cuando se expatrió durante la tiranía de Rosas. Calderón, además, cedió a inclinaciones temporales del público y de las compañías dramáticas españolas que recorrían América, formadas dentro del medievalizante romanticismo europeo." Esto último fué escrito como justificación, no como exculpante, de la actitud del autor dramático, según trataré de confirmarlo con el examen de una evasión romántica que se descubre en la menos conocida de sus obras.

Lá incertidumbre que existe en torno a Fernando Calderón Beltrán, no se limita a los datos biográficos: llega a la bibliografía, que incluye títulos de obras inexistentes. Manuel Mañón, en su Historia del Teatro Principal, le atribuye uno de Scribe, El vaso de agua, por mala lectura de un párrafo de la Reseña histórica del teatro en México, de Olavarría, y otros le han seguido en ese error, aquí y en el extranjero. Al enumerar las primeras obras que escribió, Rafael B. de la Colina, en las páginas que preceden a las obras de Calderón incluídas en la Biblioteca. de Autores Mexicanos, dice: "Por los años 1826 y 1827, Calderón, ya de regreso en Zacatecas, su país natal, escribió Reinaldo y Elina, Zadig, Zeila, Armandina, Los politicos del dia, Ramiro, Ifigenia y Hersilia y Virginia." $\mathrm{El}$ último de esos títulos, Hersilia y Virginia, corresponde a una obra impresa con título diferente. En el tomo inicial de las obras compietas de Fernando Calderón, que se publicó en Zacatecas en 1882, se halla incluida la tragedia Muerte de Virginia por la libertad de Roma, en las páginas 287 a 342 . Entre sus personajes figura Isilio, prometido de Virginia. Quizás Calderón intituló primeramente su tragedia con los nombres de ambos personajes: Isilio y Virginia, y tal título fué sustituído más tarde por aquel con que la obra ha llegado a nosotros. Convenía advertir que, en vez del título supuesto, debe quedar el de dicha tragedia, Muerte de Virginia por la libertad de Roma dividida en cuatro actos, en la cual, como es lógico, el autor sitúa la acción en la Roma antigua. Se asemeja, por ello, a alguna de las obras del cubano-mexicano José María Heredia, como Sila o como Los últimos romanos, donde - tras la dura expe- 
riencia de la anarquía que siguió al imperio de Iturbide en los años iniciales de la República- buscaba en el pasado una lección que pudiera aprovechar a nuestro país; según traté de explicarlo en un estudio sobre Los últimos romanos. Si fué así, eso indicaría que Calderón no habría desoído, como no desoyó en otras ocasiones, los consejos de Heredia, crítico ejemplar e introductor del romanticismo en nuestra literatura.

La fuente remota del asunto que trata Calderón en su tragedia, está en las Décadas de Tito Livio. Quizás desde que seguía en la Universidad de Guadalajara la carrera de abogado, tuvo oportunidad de leer las Décadas; pero también es probable que el teatro de Alfieri lo familiarizara con el tema que desarrolla. Procede su $V$ irginia de pasajes contenidos en el capítulo XI de las Décadas: "De la maldad que Appio Claudio, uno de los diez, intentó contra una virgen desposada, encendido en su amor, y cómo el padre de la doncella la mató antes que viniese en sus manos." Tito Livio refiere que cuando Appio Claudio - - en el primer año del iv siglo de la fundación de Roma- permaneció alli para defenderla, se enamoró de Virginia, hija del guerrero Lucio Virginio y prometida del Lucio Isilio, tribuno defensor del pueblo. Enloquecido porque ella rehusaba amarlo, ordenó a su servidor Marco Claudio que la reclamara, como sierva, afirmando que había nacido en su casa y era hija de una esclava suya. Pidió Virginia auxilio a los caballeros, quienes llamaron al padre, ausente en servicio de la república. El abuelo, Publio Numitor, e Isilio acudieron a defenderla. El segundo censuró públicamente a Appio Claudio, por haber suprimido "el socorro de los tribunos y la apelación del pueblo romano, que eran dos fortalezas para conservar la libertad". Appio Claudio repuso a Isilio que "alborotaba la república y sembraba discordias, por codicia que tenía del tribunado"; mas accedió a posponer el juicio, mientras llegaba el padre, a quien había mandado prender secretamente. Logró aquél escapar. de quienes tenían orden de aprehenderlo, y se presentó vestido de luto, con su hija. Indignado por la sentencia que pronunció Appio Claudio, dijo a Virginia, al hundirle un puñal en el pecho: "Este es el único medio que tengo de darte la libertad, hija mía". Isilio y Numitor mostraton al pueblo el cadáver de Virginia; maldijeron a Appio Claudio por su maldad, y el pueblo, alterado, comenzó a alentar esperanzas de que "esta maldad cometi- 
da por Appio - -dice Tito Livio- sería causa de recobrar la libertad". En los capítulos siguientes de sus Décadas se ve que esas esperanzas eran fundadas: Isilio y Lucio Virginio levantaron a los caballeros contra Appio Claudio y quienes lo acompañaban en el gobierno, y lograron la caída de aquéllos y la elección de tribunos que los sustituyeran, al adoptarse de nuevo el gobierno consular, en Roma. El sacrificio de Virginia sirvió, por consiguiente, para que los romanos recuperaran la libertad que Appio Claudio les había arrebatado.

Una situación como la que aprovechó Heredia con el propósito mencionado antes, serviría a Calderón para exaltar los sentimientos de libertad y amor a la patria, en aquellos días en que preludiaba el gobierno dictatorial de Santa Anna, por los años de 30, antes de que Calderón combatiese en la batalla de Guadalupe. La tierra donde vivían los padres del dramaturgo, fué duramente castigada por el dictador̈, cuando se le enfrentó quien la había gobernado con acierto: Francisco García. Su resuelta actitud quedó quebrantada al derrotar a las milicias de Zacatecas los veteranos de Santa Anna. Fernando Calderón, hecho prisionero al caer herido, iba a pasar después a México, al lugar elegido para su destierro, y se consideraría, por eso, como una víctima del tirano. Vencido, humillado y desposeído debió de sentirse en condiciones semejantes a aquellas en que se hallaban los habitantes de Roma, con Appio Claudio. A un romántico exaltado, como él, tenía que parecerle más dura aún la situación local, cuando Santa Anna, al manténer la unidad del país, acabó con la autonomía del Estado que se ufanaba de su libertad apoyándose en la minería, entonces próspera.

Petrarca recordó a Virginia, en dos tercetos de su "Triunfo de la castidad", y varios dramaturgos escribieron obras con el tema de su sacrificio. Entre los autores dramáticos que en diversos países y épocas aprovecharon ese pasaje de Tito Livio, se encuentran algunos en España —de Juan de la Cueva, en el xvi, a Tamayo y Baus, en el xix-, y en Italia se contó Alfieri, que tanto influiría en varios de los dramaturgos españoles e hispanoamericanos. Parte Alfiéri, en' el desarrollo de su tragedia Virginia, de un diálogo entre aquélla y su madre - Numitoria-, ajenas aún al peligro. Marco reclama a Virginia como sierva, y cuando Isilio se presenta con gente del pueblo, se retira seguro de que comparecerá ante el tri- 
bunal. Así acontece en el acto segundo, que se inicia con un monólogo de Appio Claudio. Ante los lictores, Marco insiste en su exigencia, y tras el aplazamiento del juicio, quedan solos ambos cómplices. Sc encuentra con Isilio el padre de Virginia, al volver, y a continuación se les reưnen mađre e hija. Appio Claudio se entera por Marco del retorno del padre, que se presenta a defender a su hija, quien comparece después ante el tribunal, y al dictar la sentencia Appio Claudio, sobreviene el trágico desenlace de la obra.

Fernando Calderón tuvo presente la Virginia de Alfieri, en su tragedia Muerte de Virginia por la libertad de Roma, como es fácil comprobarlo; pero mientras Alfieri distribuye el asunto en cinco actos - de acuerdo con la norma que, según los preceptistas, arranca del Edipo Rey de Sófocles, y que adoptaron, con los trágicos del siglo de oro francés, clásicos y neoclásicos-, lo condensa en cuatro Calderón. Comienza su obra con un diálogo entre Appio y Marco Claudio, en el cual traman su plan: se retira el segundo y aquél medita cómo podrá apoderarse de Virginia, que se presenta, altiva, a responderle. Isilio y Numitoria la apoyan. En el segundo acto, el de la iniciación del juicio, los tres conservan su entereza. Al quedar solo, Appio expresa su desdén hacia el adulador cómplice. En el tercer acto Marco Claudio trata de comprar a Isilio, que se indigna al oír su proposición. Virginia procura calmarlo. El padre menciona los males sufridos por la patria y comunica su fervor a la hija y la esposa. Al hablar con Appio, intenta hacerle comprender su error; rechaza una tentativa de soborno y se retira, para desahogar ante los suyos el dolor que le produce la falta de libertad en su patria. En el acto final, tras la muerte de Virginia, Isilio quiere morir también; pero el padre lo convence de que debe seguir luchando.

Calderón trató el tema con aliento juvenil. No planteó el conflicto mesuradamente, como el poeta italiano; hay mayor decisión en su desarrollo, por la valentía con que varios de los personajes se expresan y por el acelerado ritmo que da a las escenas finales. Además de que condensa en dos actos los tres últimos de la Virginia de Alfieri, la Muerte de Virginia por la libertad de Roma se aleja del modelo italiano, en varios puntos. Calderón parte de la escena en que Appio y Marco Claudio urden la trama para apoderarse de Virginia; escena que Alfieri omitió, sin duda por creerla in- 
necesaria, ya que escribía para un público familiarizado con el punto de partida: las Décadas de Tito Livio. Otro tanto acontece con la escena de la fracasada seducción de Virginia, que Calderón, a diferencia de Alfieri, consideró indispensable incluir en su obra, para que el espectador no conozca el hecho sólo por referencias sino directamente, al preciar la escena. En cuanto a Isilio, a quien manda matar Appio en la obra de Alfieri, sobrevive en la de Calderón, como instrumento para realizar el castigo del tirano. De este modo, nuestro dramaturgo se mantiene fiel a la historia.

Coinciden ambos autores en su odio a la tiranía y en su amor a la libertad y la patria; pero Calderón, que no olvida los sentimientos de honor y dignidad humana propios del tema, subraya el amor patrio y la aversión a los tiranos; sobre todo. Para él Appio encarna al tirano detestable; de su cómplice hace el indigno adulador, necesario para que aquél exista. Da al primero los rasgos del autócrata que no admite objeciones de sus súbditos ni los considera capaces de nobleza alguna. Isilio y Virginia representan la dignidad, la virtud, el honor que no transige. Los padres de la doncella exaltan con su actitud el amor patrio, el amor a la libertad; pero no son únicamente estos dos personajes los que la defienden. La Virginia de Calderón se conduce con valentía y habla al tirano del terrible futuro que le espera, cuando la patria se alce contra él. No acepta ser esclava del poderoso: prefiere amar al que ha elegido libremente. Isilio es además un patriota; hombre de acción que va a donde se propone. Por eso dice:

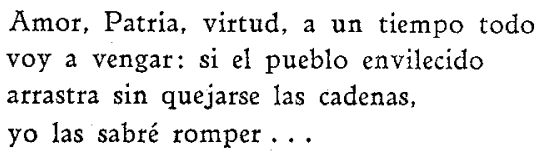

En cuanto al padre de Virginia, expresa vehemente sentimientos que experimentaría Calderón en sus mocedades. Puede hallarse más honda resonancia que en los versos blancos - sciolti- de Alfieri, en los endecasilabos asonantados - romance heroico- de Calderón, cuando Virginia habla de la patria privada de libertad:

iLa patria:, ¿dónde está? No deis tal nombre

a la tumba de siervos degradada

que tiembla ante el tirano que la oprime.

Nada tenemos ya: baldón, infamia, 
servidumbre crüel, oprobios, hierros, es nuestra suerte aquí. ¿Tenemos patria y se nos arrebatan nuestras hijas para ser oprimidas y violadas por el tirano vil, quedando impune tan horrenda maldad? ¿Tenemos patria y se nos arrebatan nuestros bienes para aumentar el fausto y pompa vana de nuestros opresores, cuyo lujo insulta al miserable que trabaja para vivir, y cuyos pobres frutos en nombre del Estado le arrebatan? ¿Tenemos patria y no tenemos leyes? ¿O son siniestramente interpretadas por el tirano, siendo en vez de apoyo para los ciudadanos, un fantasma aterrador, con cuyo augusto nombre se escudan los delitos y la infamia de los agentes del poder? No existe (con fuego) Patria sin libertad...

No hay espacio aquí para comparar detenidamente ambas obras, ni. sería esta ocasión la adecuada para hacerlo; mas por lo transcrito se puede advertir que ese motivo, los ultrajes a la libertad y la ausencia de la ley, adquiere especial importancia en la tragedia de Calderón que - no lo olvidemos - pensaba como abogado, y había experimentado, además, en carne propia el dolor producido por la opresión que priva de su libertad a los hombres. Para Alfieri, que no estaba satisfecho de su obra, la castidad de Virginia puesta à salvo por su sacrificio - hacia el que va tan resuelta como Ifigenia en Aulide - y la firme determinación del padre que con la muerte le da la libertad, constituyen los puntos cimeros de la obra. Calderón ve en el asunto, más bien, un pretexto para insistir en la degradación que produce la falta de libertad -al mostrar la vergüenza de los ciudadanos de Roma convertidos en esclavos - y exponer el mayor sacrificio a que se puede llegar, para recobrar aquélla: el del padre que da muerte a su propia hija, por impedir que sea deshonrada.

Calderón sufría, en sí y en los allegados, aquello de que habla en sus versos. Por boca de los personajes de su tragedia, lanza al tirano indefinido, aquel que pintó en "El sueño del tirano", los más enérgicos apóstrofes. La muerte de Virginia por la libertad de Roma es una resuelta condenación de la tiranía. De haberse podido repre- 
sentar en México, en los días de la dictadura de Santa Anna, habría comunicado a los espectadores la pasión que el autor puso en esa descripción de la Roma envilecida; mas para ello tenía que acudir al subterfugio de situar en la antigua Roma, y entre romanos, la acción de una obra que aludía a la situación local, según la veía el dramaturgo. De análoga manera procedieron, en fecha no muy distante de nuestros dias, Anouilh y otros dramaturgos, durante la invasión, en Francia.

Basta lo observado en esa obra, para rectificar el concepto que hasta ahora se ha tenido de Calderón, como autor dramático. En sus dramas: los caballerescos - El torneo y Hermán o la vuelta del cruzado- - y el histórico - Ana Bolena-, también sería posible encontrar pasajes veladamente alusivos a sus preocupaciones, en relación con la época en que vivió y en la cual esas obras fueron representadas y publicadas. Tales alusiones posiblemente no pasaron inadvertidas para sus contemporáneos, a quienes las destinaba. Si no las percibimos con facilidad nosotros, es porque nos hallamos, en relación con él y sus coetáneos, a distancia de más de un siglo; y un siglo, en la rápida evolución de un país como el nuestro, significa mucho. En un centenar de años, caen en el olvido innumerables elementos y se pierden matices que sólo podrían advertir, ahora, el sociólogo perspicaz, el investigador atento y penetrante, el historiador especializado en la vida del siglo XIX y particularmente en el romanticismo.

La obra examinada aquí, representa una evasión ; mas no infructuosa ni estéril, como otras evasiones románticas; porque cuando Calderón se evade, en el espacio y en el tiempo, lleva consigo preocupaciones, sentimientos y pensamientos que son los de su época. atunque sitúe la acción en Roma, cuatro siglos después de fundada. Es una evasión que se explica por la imposibilidad en que se hallaba de expresar sus sentimientos como hubiera querido hacerlo: directamente, ante el público, en tiempo de restricciones atenuadas sólo por la comprensiva tolerancia del Ministro de la Guerra, José Maria Tornel, que escribió en favor suyo aquellas palabras: "Ios talentos deben respetarse por las revoluciones." Es la viril evasión que el ingenio busca, en las épocas en que algo le impide expresar sus ideas libremente. 
